\title{
EVIDENCE BASED LEARNING: A STUDY OF IMPACT ON EXPERIENTIAL LEARNING ACTIVITIES ON ATTAINMENT OF SPECIFIC LEARNING OUTCOMES
}

\author{
Prashant Thote ${ }^{*}{ }^{\square}$, Gowri. S ${ }^{2}$ \\ *1, 2 Gyanodaya Vidya Mandir, India
}

DOI: https://doi.org/10.29121/granthaalayah.v9.i2.2021.3225

Article Type: Research Article

Article Citation: Prashant Thote, and Gowri. S. (2021). EVIDENCE BASED LEARNING: A STUDY OF IMPACT ON EXPERIENTIAL LEARNING ACTIVITIES ON ATTAINMENT OF SPECIFIC LEARNING OUTCOMES. International Journal of Research GRANTHAALAYAH, 9(2), 22-31. https://doi.org/10.29121/granthaa layah.v9.i2.2021.3225

Received Date: 19 January 2021

Accepted Date: 18 February 2021

Keywords:

Colligative

Solutions

Solute

Solvent

Experiential Learning

\begin{abstract}
The unit "Solution and its Colligative Properties" is found to be difficult for most of the Grade 12 students. To make the learning experience joyfulthree experiential learning activities are designed. It plays a positive role in strengthening and enhancing the academic performance in Chemistry. The objective of the present paper is to inspect the impact of the designed three experiential learning activities on attainment of intended specific learning outcomes. Totally 40 students participate in the study. The purposive sample technique is used to draw the sample of the present study. Sample learners are divided into two groups: study group and control group. Each group consists of 20 students. Both groups are taught the unit "Solution" through online mode due to COVID pandemic. The pretest - "formative assessment" is conducted. The result of the formative assessment divulges that the learners face challenges in the conceptual understanding of the unit. The researcher designs three activities for experiential learning to enhance the deep conceptual understanding. Students of the study group are exposed to the experiential learning activities for the period of one week. The present paper is experiential in nature. Formative assessment is conducted before and after the treatment. Data is collected by using two formative assessments and one summative assessment. Statistical tool used are mean, mean difference and standard deviation. The result of the paper reveals that experiential learning has positive impact on attainment of specific learning outcomes. Low score learners are much benefitted than the average learner and the high score learners. Based on the conclusion of the study few recommendations are made.
\end{abstract}

\section{INTRODUCTION}

"Learning is not a product of teaching; learning is the product of activity of the learners"

The joy of learning magnetizes the thrust of deep learning, curiosity, passion, collaboration, connection, efforts, pride and sharing. For creating a joyful learning environment, teachers have to play a vital role. It is the responsibility of the teachers for nurturing and creating safe and vibrant classroom where they connect with the learners.

(C) 2021 The Author(s). This is an open access article distributed under the terms of the Creative Commons Attribution License, which permits unrestricted use, distribution, and reproduction in any medium, provided the original author and source are credited. 
Chemistry is a logical based science subject with huge application in daily life. It consists of abstract concept and to manifest it and to master, it requires gradual and sound understanding of the concept and the subject. The lower attainment of specific learning outcomes indicates ambiguity in understanding the concept. Mostly, in subject like Chemistry the concepts are interlinked and inter-connected and profound conceptual understanding to acquire correct and sound understanding is essential.

"Solution" is the unit two of All India Senior Secondary School Certificate Examination, it contains colligative properties of the solution. The most common problem that the students face is: they do not have satisfactory conceptual understanding which leads to poor conceptual understanding, alternative conceptual formation, misconception and stressful learning experiences. The poor conceptual understanding in the unit "Solution" includes effect of non-volatile solute, sub-microscopic images of the evaporation process of non-electrolytic and electrolytic component in accordance to their difference in boiling point, osmotic pressure and relationship among lowering of vapour pressure, elevation in boiling point and depression in present point, molar mass and Vont's Hoff factor. Our previous study reveals that "Solution" is the most difficult unit for students to learn.

The unit two has colligative property as a sub-topic. There are certain properties of solutions which depend on the number of solute particles (molecules or ions) in definite solvent and independent upon all other physical and chemical properties of solute and solvent. Major colligative properties associated with solutions are:

- Relative lowering of vapour pressure

- Elevation in boiling point temperature

- Depression in freeing point temperature

- Osmotic pressure

The colligative properties of solutions depend on concentration of solute and not on the chemical identity of solute and solvent such as molecular mass. The structure of Sodium Chloride and Sugar are quite different but impact of both of them on the properties of the solution is dependent upon the number of molecules present in the solution. Vapour pressure of a solution is the pressure exerted by the vapours of the liquid in equilibrium with liquid at a given temperature. When nonvolatile solute is added to volatile solvent, vapour pressure of a solution is lowered. It is due to the solute molecules which occupies the space at top layer of the solution and hence it decreases the amount of solvent that may be released.

The temperature when the liquid begins to boil is called the boiling point of the liquid or the pressure of the surface area of the liquid becomes equal to the external the atmospheric pressure. The boiling point of the liquid is called normal boiling point when the external pressure is normal. If small amount of non-volatile solute is added further to the volatile solvent (eg. water) the vapor pressure of the solution formed will decrease. It means that solution has to heated at higher temperature in order bring its vapour pressure equal to its atmospheric pressure. The boiling point of the solution increases and its physical properties of the solution changes under a particular set of conditions.

The freezing point of the liquid is the temperature at which the liquid begins to freeze or solidify. It is the same temperature at which the solid begins to melt. At this temperature both solid and liquid states of the substance coexist and are in the state of equilibrium and have the same vapour pressure. The solution will be intact and freeze when its vapour pressure equals to the vapor pressure of pure solid solvent. If non-volatile solute is added to the volatile solvent the freezing point temperature of the solvent get decreased. The decrease in the freezing point is due to the solute that interacts with the normal crystallization process of a solvent and results in lowering of temperature.

The osmatic pressure is the one that develops due to osmosis at a particular temperature. The change in osmatic pressure changes the movement of the solvent across the semipermeable membrane and the system tries to establish equilibrium as soon as possible. Increasing concentration of non-volatile solute in a volatile solvent increases the atmospheric pressure.

\section{Statement of the problem}

The present study is planned to explore the impact of experiential learning activities on the attainment of specific learning outcomes amongst the learners of All India Senior Secondary School Certificate Examination. Hence the statement of the problem is entitled as "Evidence based learning: A study of impact on experiential learning activities on attainment of specific learning outcomes" 


\section{Objectives of the study}

Subsequent objectives are designed to guide the study:

1) To explore the effect of experiential learning on the attainment of specific learning outcomes of the learners of study group and control group.

2) To suggest the workable experiential learning activities for joyful learning experiences and to enhance the deep conceptual understanding.

\section{METHODS}

\section{Hypothesis}

Five null hypotheses are fabricated to guide the study and to collect the data.

H01: There is no noteworthy variance in the attainment of specific learning objectives amongst the learners of study group and the control group on the formative assessment before the treatment.

Ho2: There is no noteworthy variance in the attainment of specific learning objectives amongst the learners of study group and the control group on the formative assessment after the treatment.

Ho3: There is no noteworthy variance in the attainment of specific learning objectives amongst boys and girls of study group on the formative assessment after the treatment.

Ho4: There is no noteworthy variance in the attainment of specific learning objectives amongst the learners of study group on the summative evaluation after the treatment.

Ho5: There is no noteworthy variance in the attainment of specific learning objectives amongst the low, medium and higher achiever of study group on the summative evaluation after the treatment.

\section{Research Design}

Experimental research design is employed in the present study. The formative assessment is conducted before and after the study. Students are randomly selected and are divided into two groups: study group and control group. The symbolic representation is as follows:

$$
\begin{array}{lll}
R S=01 & T & 02 \\
R C=03 & T & 04
\end{array}
$$

Where
$\mathrm{R} \longrightarrow$ Randomly selected
$\mathrm{S} \longrightarrow$ Study group
$\mathrm{C} \longrightarrow$ Control group
$\mathrm{O} \longrightarrow$ Observation
$\mathrm{T} \longrightarrow$ Experimental treatment

\section{Population}

All students appearing for All India Senior secondary School Certificate exam in the academic year 2020-21 in the study area.

\section{Sample}

Purposive and snowball sampling technique is used to draw the sample of the study. Totally 40 students participate in the study. The samples are divided into two groups: study group and control group. Each group consists of 20 students.

Table 1: Sample for the present study

\begin{tabular}{|c|c|c|}
\hline Gender & Study group & Control group \\
\hline Boys & 10 & 10 \\
\hline Girls & 10 & 10 \\
\hline
\end{tabular}


Prashant Thote, and Gowri. S

\section{De-Limitations}

\begin{tabular}{|l|l|l|} 
Total & 20 & 20 \\
\hline
\end{tabular}

1) The study is delimited to the students of only one school

2) The study is delimited to only coeducational school

3) The study is delimited to only rural school in industrial township,

4) The study is delimited to only one unit of Chemistry "Solutions"

\section{Tool}

The present study is experimental in nature. Due to pandemic in the academic year 2020-21, online classes are conducted. The unit "Solutions" is covered under online mode. Before switching over to the classroom instructions the formative assessment is conducted to assess the conceptual understanding of the unit. The results illustrate that the students are having poor conceptual understanding and hence three experiential activities are designed to enhance the conceptual understanding in colligative properties. The formative assessment is conducted after the treatment when students of the study group are exposed to the experiential learning activities. At the end of the academic year summative evaluation is conducted. Two formative assessments and one summative evaluation are the tools to collect the data.

\section{Treatment}

Activity 1: (Lowering of vapour pressure and elevation of boiling point)

\section{Specific Learning outcomes}

1) The learners after conducting the experiential learning activities will be able to:

2) State the colligative properties of the solution with example from day-to-day life.

3) Explain the addition of non-volatile solute (sugar/common salt) with volatile solvent (water) and its impact on vapour pressure of the solvent.

4) Describe the colligative properties of the solution that changes with increasing concentration of the solute in the solvent.

\section{Materials required}

1) Busen burner

2) Sauce Pan

3) Sugar

4) Measuring cylinder

5) Thermometer.

\section{Procedure}

1) The study group students are divided into two groups. Each group is provided with water and sugar to make 1:2 and 1:4 volume by volume solutions. Here water acts as the dependent variable. Measuring cylinder is used to measure the volume of the solute (sugar) and the solvent (water) and poured into sauce pan,

2) The sauce pan is heated and the solution is constantly stirred until it boils. The boiling point of the solution is measured using thermometer. Learners observe the consistency and the colour of the solution.

3) After boiling the solution it is poured into the cooking sheet and allowed to cool. Students are asked to check the consistency by chewing and to check the bitterness of the solution.

\section{Activity Two:(Osmatic Pressure)}

\section{Specific Learning Outcomes}

The learners after performing the activities will be able to:

Explain the interactions among the solutions.

1) Use of retro meter to measure soluble solvent in the solution.

2) Impact of water on the growth of microbes.

3) Impact of osmatic pressure on microorganisms. 


\section{Materials Required}
1) Fresh grapes
2) Preserved food
3) Retro meter

\section{Procedure}

1) Learners measure soluble solvent in fruits and its concentration with the help of retro meter. Sugar concentration in the fresh fruit juice and preserved fruits are measured with the help of retro meter.

2) Increase in sugar concentration in the fruit juices (both fresh and preserved) increases the refractive index.

3) Students measure and record the amount of solute (sugar) in the solution (water, fresh juice and preserved items like jam and jelly).

4) Students learn that many preserved food items have higher concentration of sugar and salt as compared to fresh fruits juice. The concentration of the solute in the solvent lowers the water activity and increases the osmatic pressure on the microbial cell.

Activity three (Depression in freezing point)

\section{Specific Learning Outcomes:}

Learners after performing the experiment will be able to:

1) Explain the concept of food products.

2) List the source of nutrition's from the ingredients - such as protein from milk, fat from cream etc.,

3) Explain the functional properties with refence to colligative properties.

\section{Materials Required}

1) Product information about the products used.

2) Empty container of the product.

3) Milk

4) Carageen

\section{Procedure}

1) Learners collect the empty container of various frozen products such as chocolate and ice creams. These are sugar added frozen products.

2) Additives are added to give texture to the products. Their functions are not known to the learners.

3) Small quantity of milk and carageen are given to the learners and are asked to mix them. Learners compare the texture of milk before and after mixing with the carageen.

4) Learners are prompted to draw a long chain of sugar and link it with other chains of calcium at the centre.
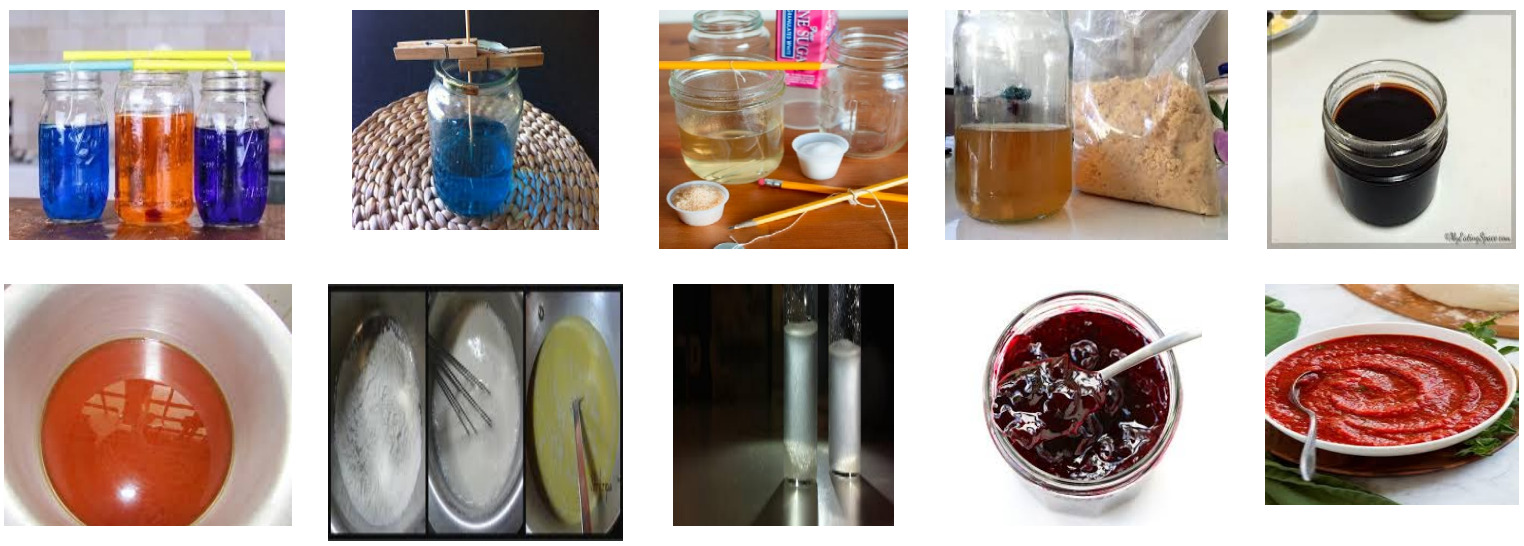

Figure 1: Lab Activities 


\section{Analysis of the Data}

Data is obtained from the formative assessment before and after the treatment and through summative evaluation at the end of the academic year (pre-board) and are presented in the tabular form. The Mean, Mean difference and SD are calculated for both the groups and are tested at 0.05 level by applying t-test.

\section{RESULT AND DISCUSSIONS}

Ho1: There is no noteworthy variance in the attainment of specific learning objectives amongst the learners of study group and the control group on the formative assessment before the treatment.

Table 2: Significant mean difference of formative assessment before the treatment between the students of study and control group

\begin{tabular}{|c|c|c|c|c|c|c|}
\hline Group & N & Mean & SD & SE & t-value & p-value \\
\hline Study Group & 20 & 66.60 & 8.3 & 0.72 & 0.072 & 0.94 \\
\hline Control Group & 20 & 54.18 & 8.7 & & & \\
\hline
\end{tabular}

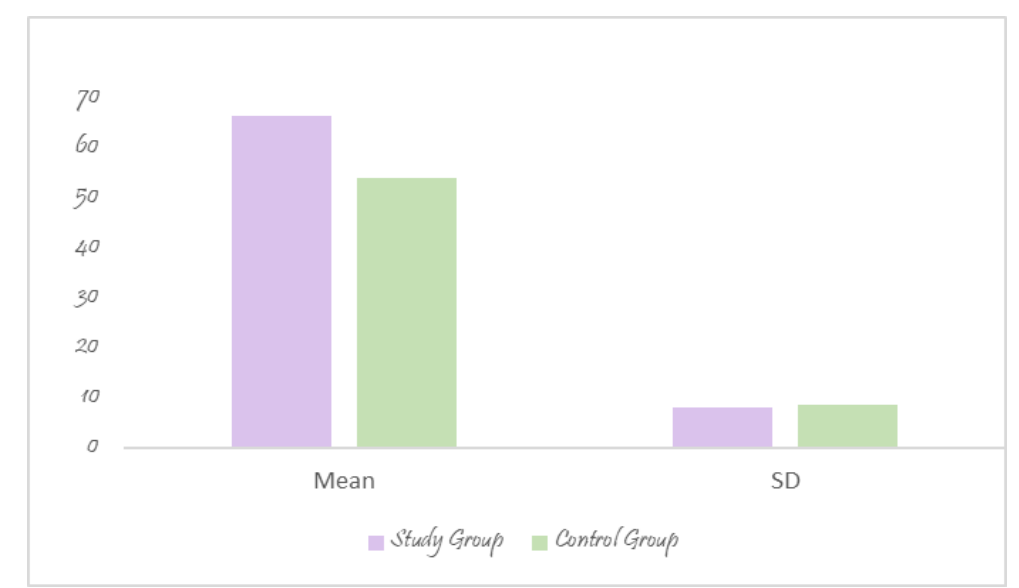

Figure 2: Students performance in Formative assessment before treatment

Ho2: There is no noteworthy variance in the attainment of specific learning objectives amongst the learners of study group and the control group on the formative assessment after the treatment.

Table 3: Significant mean difference of formative assessment after the treatment between the students of study and control group

\begin{tabular}{|c|c|c|c|c|c|c|}
\hline Group & N & Mean & SD & SE & t-value & p-value \\
\hline Study Group & 20 & 91.40 & 1.75 & 0.92 & 26.12 & 0.00 \\
\hline Control Group & 20 & 65.92 & 3.53 & & & \\
\hline
\end{tabular}


Evidence Based Learning: A Study of Impact on Experiential Learning Activities on Attainment of Specific Learning Outcomes

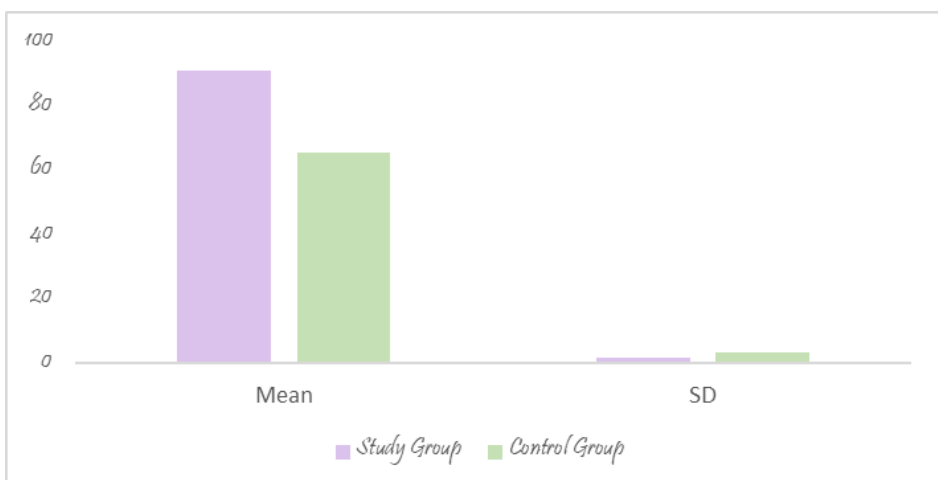

Figure 3: Students performance in formative assessment after treatment

Ho3: There is no noteworthy variance in the attainment of specific learning objectives amongst boys and girls of study group on the formative assessment after the treatment.

Table 4: Significant mean difference of formative assessment after the treatment between boys and girls of the study group

\begin{tabular}{|c|c|c|c|c|c|c|}
\hline Gender & $\mathrm{N}$ & Mean & SD & SE & t-value & p-value \\
\hline Boys & 20 & 67.40 & 7.52 & \multirow{2}{*}{0.76} & \multirow{2}{*}{0.612} & \multirow{2}{*}{0.058} \\
\hline Girls & 20 & 65.90 & 9.04 & & & \\
\hline
\end{tabular}

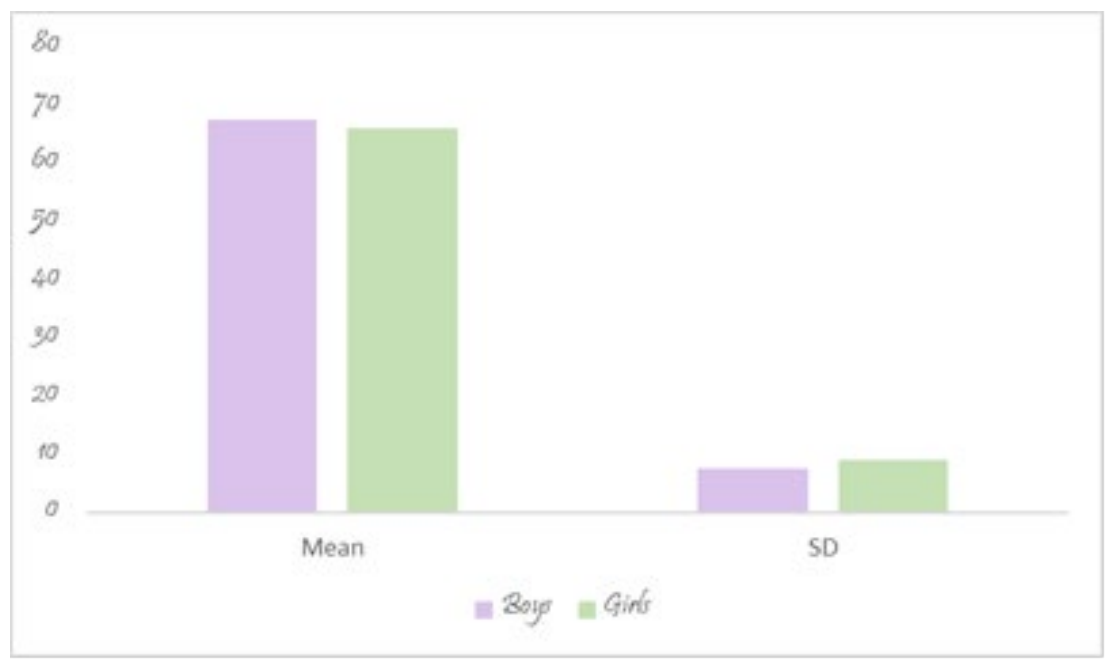

Figure 4: Performance of Boys and Girls in formative assessment after treatment

Ho4: There is no noteworthy variance in the attainment of specific learning objectives amongst the learners of study group on the summative evaluation after the treatment.

Table 5: Significant mean difference of summative evaluation after the treatment of the study and control group

Significant $(\mathrm{p}<0.05) ; \mathrm{df}=38$

\begin{tabular}{|c|c|c|c|c|c|c|}
\hline Group & N & Mean & SD & SE & t-value & p-value \\
\hline Study Group & 20 & 84.17 & 8.3 & 0.62 & 32.33 & 0.00 \\
\cline { 1 - 5 } Control Group & 20 & 54.60 & 4.3 & & & \\
\hline
\end{tabular}

t-value at $0.05=2.02$ 
Prashant Thote, and Gowri. S

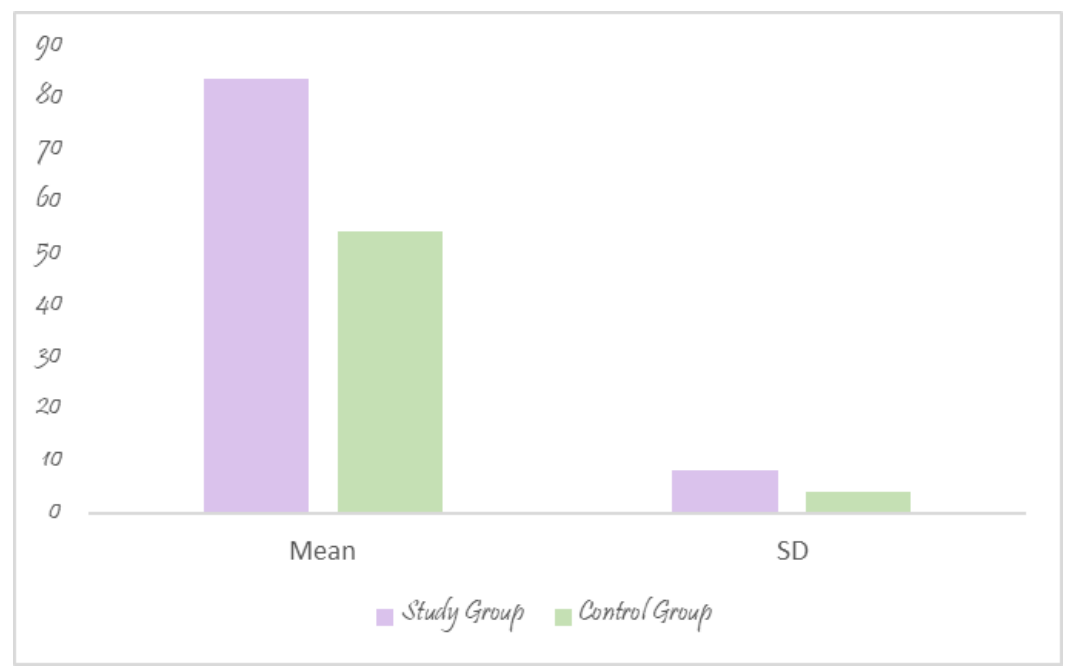

Figure 5: Students performance in summative evaluation

Ho5: There is no noteworthy variance in the attainment of specific learning objectives amongst the low, medium and higher achiever of study group on the summative evaluation after the treatment.

Table 6: post-hoc test on attainment of Specific Learning Outcomes of the study group

\begin{tabular}{|c|c|c|}
\hline Scores & N & Mean \\
\hline High Scores & 03 & 26.11 \\
\hline Average Scores & 10 & 32.85 \\
\hline Low Scores & 07 & 32.11 \\
\hline
\end{tabular}

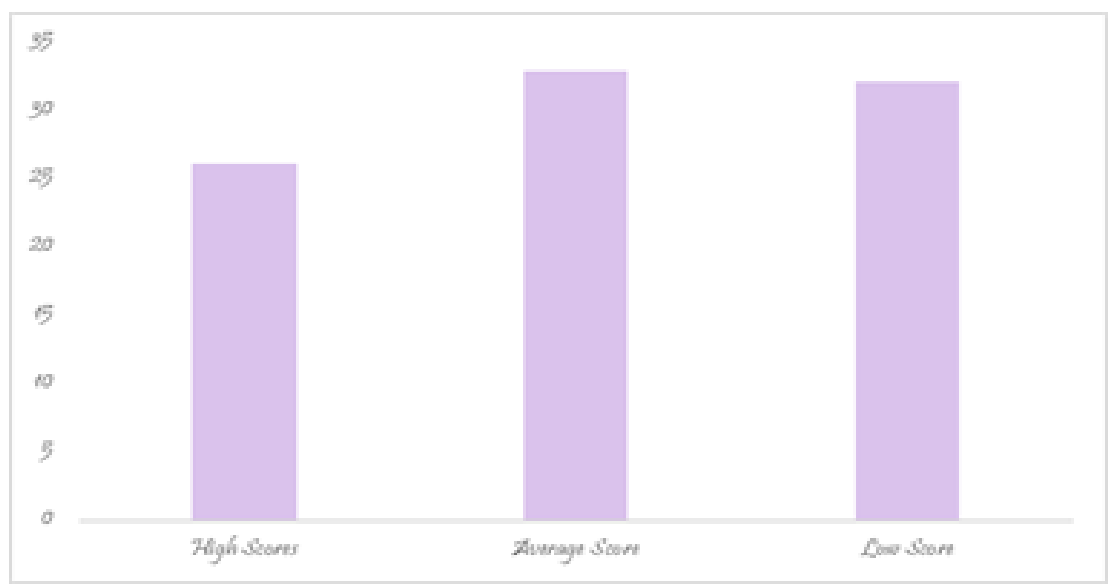

Figure 6: Mean score of high, average and low performance of students

Table 2 depicts the calculated value of $t$ is found to be 0.042 and it is statistically non-significant as it is less than the critical table value of $t$ at 0.05 level. Therefore, the null hypothesis "There is no noteworthy variance in the attainment of specific learning objectives amongst the learners of study group and the control group on the formative assessment before the treatment" is accepted. It shows that the performance of both the study group and the control group in the formative assessment before the treatment is same (Fig 2).

Table 3 illustrates that the calculated t value is found to be 26.12. It is statistically significant and higher than the critical $t$ value at 0.05 level. Therefore, the null hypotheses "There is no noteworthy variance in the attainment of specific learning objectives amongst the learners of study group and the control group on the formative assessment after the treatment" is rejected. It shows that the experiential learning activities have a positive impact on attaining the specific learning outcomes among the students of study group (Fig 3).

Table 4 shows that the computed t-value is found to be 0.0412 . It is statistically insignificant, as it is less than the critical value at 0.05 level and therefore the null hypothesis "There is no noteworthy variance in the attainment 
of specific learning objectives amongst boys and girls of study group on the formative assessment after the treatment" is accepted. There is no ambiguity in the performance of both boys and girls after the treatment. Both are equally benefitted from the experiential learning activities. (Fig 4).

Table 5 indicates that the calculate value of $t$ is found to be 32.33. It is statistically significant and higher than the table value of $t$ at 0.05 level. Hence the null hypothesis "There is no noteworthy variance in the attainment of specific learning objectives amongst the learners of study group on the summative evaluation after the treatment" is rejected. It shows that the learners of study group exhibit higher attainment of specific learning outcomes as compared to the students of control group (Fig 5).

Table 6 reveals that low scoring and average scoring students have higher mean than the high scorers. It shows that experiential learning activities have significantly much higher positive impact on the attainment of specific learning outcomes (Fig 6).

\section{Discussion}

Most of the students are aware and can make confectionary products at home. Experiential learning activities deal with the basic vocabulary of unit "Solutions" such as solute, solvent, saturated solution, boiling point, freezing point and osmatic pressure. Teachers raise questions during experiential learning activity to reinforce the concept. Experiential learning activity one illustrates that the amount of sugar added to the solution changes the colour of the solution. Chemical structures of the sugar and salt are provided to the students of the study group to compare the size of the molecules. The structure of sucrose and fructose are also given to the students to compare along with the sugar and salt. Students are asked to prepare hypotheses before each of the experiential learning activity- such as whether the concentration or the size of the molecules has an impact on the properties of the solution. To compare the colligative properties such as boiling point -the activity is done by using two sugar solutions. The concept of adding non-volatile solute to the volatile solvent increases the vapour pressure. In the experiential learning activity one addition of sugar increases the concentration of solution therefore the temperature of the boil point increases. In this experiment elevation of the boiling point is discussed with students.

The experiential learning activity two is planned for explaining the colligative property of as osmatic pressure. The students are aware that products like pickle, jam, honey have long life and stability. In many food products it is necessary to limit the water usage in order to avoid spoilage due to microbial growth. In this experiential learning activity water quantity is not measured in food products. Addition of sugar increases the osmatic pressure which in turn kills the microbes due to the concentration of the solute. Solvent move into the microbes (system) through the cell-membrane also called semi-permeable membrane.

In experiential learning activity three students are able to compare the solid structure of the chocolate and the ice-cream. Students are asked to identify the ingredients of ice-cream and its role. The solution is prepared and kept to freeze. The solution is stirred to incorporate the air to enhance the smoothness of the mixture. The colligative properties like depression in freezing point related with ice-cream are discussed with students. Sugar as non-volatile solute in the solvent (milk) interacts with casein (milk protein) to form a complex structure. The viscosity of both products and reactant is compared. The solute (sugar) is added to solvent (milk) which contribute to the texture of the solution (ice-cream). The activity also includes the discussion about foam and emulsion. At the end of this activity students are able to understand that additives of sugar as non-volatile solute depress the freezing point of the solution (ice-cream).

Students are aware that during the preparation of ice cream salt is added to ice to explain the colligative property of depression in freezing point. Teachers also discusses why salt is preferred over sugar in depression of freezing point. The concept is illustrated with a model of how the solute in solution changes the colligative property of freezing point. Students also come to know that sweetness is not only the reason for adding sugar to food products.

\section{Conclusion}

- Experiential learning activities foster the concept of role of the solute in colligative properties of the solution. The concept of colligative properties has a role in day to day life.

- Result of the study shows that there is a significant positive effect of experiential learning activity on the attainment of specific learning outcomes among the students in Chemistry. Providing joyful learning 
experiences not only increases the academic performance but also make students to actively participate in learning process and the motivation level of the learners increases.

- Learners of the study group show much better performance in the attainment of specific learning outcomes. It is also found that there is high satisfaction and motivational level. Retention of knowledge is also developed among the students of the study group.

- In nutshell it can be concluded that experiential learning activities have significant positive effect on the attainment of specific learning outcomes.

\section{Recommendations}

- Hands on experiential learning activities are very effective tool to raise attainment of specific learning outcomes in subject like Chemistry. It is strongly recommended to enhance the achievement level of the subject.

- In service training programme on regular basis for designing experiential learning activities are essential and continuous improvement in competence amongst the faculty members is a catalyst.

\section{SOURCES OF FUNDING}

This research received no specific grant from any funding agency in the public, commercial, or not-for-profit sectors.

\section{CONFLICT OF INTEREST}

The author have declared that no competing interests exist.

\section{ACKNOWLEDGMENT}

None.

\section{REFERENCES}

[1] Prashant Thote, Experiential Learning: Inclusive Art Education for Joyful Learning, Review of Research, Vol 8, Issue- 09, June 2019.

[2] Prashant Thote, Experiential Learning: Model for Teaching Science at Grade Nine, Research Magma, Vol-3, Issue -06, August - 2019.

[3] Prashant Thote, An Analysis of Impact of Evidence Based Learning on Academic Achievement of Students, International Journal of Research- Granthaalayah, Vol 8, Issue- 08, August 2020.

[4] Prashant Thote, Experiential Learning: An Analysis of Impact on Academic Achievement Among Students of Grade 12, International Journal of Research- Granthaalayah, Vol 8, Issue- 09, September 2020.

[5] Prashant Thote, Evidence Based Learning: An Analysis of Impact on Retention of Knowledge, International Journal of Research- Granthaalayah, Vol 8, Issue- 10, October 2020.

[6] Prashant Thote, Outcome Based Learning: An Analysis of Impact on Academic Achievement Among School Students, International Journal of Research- Granthaalayah, Vol 8, Issue- 11, November 2020.

[7] Prashant Thote, Evidence Based Learning: An Analysis of Impact of Remedial Teaching on Conceptual Understanding, International Journal of Research- Granthaalayah, Vol 8, Issue- 12, December 2020.

[8] Prashant Thote, Evidence Based Learning: An Analysis of Impact of Experiential Learning on Attainment of Intended Specific Learning Outcome,, International Journal of Research- Granthaalayah, Vol 9, Issue- 1, January 2021. 